Mid-American Review of Sociology

Kriesberg, Louis

1962 "The bases of occupational prestige: the case of dentists." American Sociological Review 27:238-244.

McCarthy, John and Mayer Zald

1973 The Trend in Social Movements in America: Professionalization and Resource Mobilization, (Module) Morristown, N.J.: General Learning Press.

Marcuse, Herbert

1964 One-Dimensional Man. Boston: Beacon Press.

1968 "Industrialization and capitalism in the work of Max Weber." In Negations. Boston: Beacon Press.

Mead, George Herbert

1934 Mind, Self and Society. Chicago: University of Chicago Press.

Morris, Norval

1974 The Future of Imprisonment. Chicago: University of Chicago Press. Oberschall, Anthony

1973 Social Conflict and Social Movements. Englewood Cliffs, N.J.: Prentice-Hall.

Piaget, Jean

1971 Structuralism. New York: Basic Books.

Stoll, Clarice

1975 "Images of man and social control." In Ronald Akers and Richard Hawkins (ed.), Law and Control in Society. Englewood Cliffs, N.J.: Prentice-Hall.

Szasz, Thomas

1961 The Myth of Mental Illness. New York: Dell Publishing Company. Tilly, Charles

1969 "Collective violence in European perspective." In Hugh D. Graham and Ted Gurr (eds.), The History of Violence in America. New York: Bantam Books.

1978 From Mobilization to Revolution. New York : Addison-Wesley.

Weber, Max

1949 Methodology of the Social Sciences. Glencoe, Ill.: The Free Press.

Weinberg, Ian

1974 "Social problems that are no more." In Erwin Smigel (ed.), Handbook on the Study of Social Problems. Chicago: Rand McNally.

White, Hayden

1973 "Foucault decoded: notes from underground." History and Theory. 294-326.

Wilensky, Harold and Charles Lebaux

1958 Industrial Society and Social Welfare. New York: Russell Sage Foundation.

Wilson, James

1975 Thinking About Crime. New York: Vintage Books.

\section{THEORY CONSTRUCTION IN SOCIOLOGY: THE COMPETING APPROACHES}

\author{
Robert John \\ University of Kansas
}

Mid-American Review of Sociology, 1980, Vol. V, No. 1:15-36

Over the last thirty years a number of sociologists have addressed the prospects of transforming sociology into a truly scientific discipline. This project has been translated into an ongoing debate between various proponents of opposing viewpoints in the literature on construction. In this paper I propose to analyze and compare the three major approaches toward theory construction, and the methods to which they adhere. In accomplishing this task I will concentrate on three main exemplars of these competing approaches: "grounded" theory advanced by Barney G. Glaser and Anselm L. Strauss; "propositional" theory by Hubert M. Blalock; and "exact" theory by David Willer.

\section{BACKGROUND}

Recoiling from the sterile formalism of Talcott Parsons, Robert Merton (1949) made the call for "middle-range" theories, and those engaged in empirical endeavors proceeded to carry this injunction forward. This shift toward "middle-range" theories sought to avoid the dual pitfalls of speculation and the mere collection of empirical trivia. The sentiment that sociology would progress toward maturity as a science through modest short-range theoretical goals served to focus effort on the substantive areas of sociology. Merton believed that once solid theories had been developed for a number of the substantive areas they could then be unified into more comprehensive theoretical systems until the ultimate goal of grand theory was achieved.

The following decade represents the ascendence of quantitative methods and a corresponding decline of the qualitative methods that were common prior to 1940. In 1954 the first edition of Hans Zetterberg's On Theory and Verification in Sociology 
gave systematic expression to the "propositional"1 approach in the construction of sociological theory. This conception has since built the most substantial following in sociology, and the version developed by Hubert Blalock is representative of the propositional approach to theory as it is currently practiced.

A wave of reaction against propositional theory began in the mid-1960s with the revival of an approach to theory construction that was compatible with previously developed qualitative methods. Glaser and Strauss (1967:viii), dissatisfied with the relative stagnation of theory, identified the problem as an "undue emphasis on verification." Their goal was the generation of theory from data, hence theory was to be generated by and grounded in empirical reality. S.T. Bruyn (1967) supplemented the underpinning of a grounded theory by placing emphasis on the essentially phenomenological basis of the qualitative approach, and the concomitant importance of the operation of mind and the creation of meaning, topics that Glaser and Strauss failed to develop.

The final approach to theory is that developed by David Willer. The emergence of "exact" theory is best explained through an abbreviated intellectual biography of Willer. In 1967 he published Scientific Sociology: Theory and Method which was an attempt to translate the ideas of logical-positivism into sociological practice. This book subscribed to the tenets of propositional theory and placed him within the mainstream of this approach.

The next work (1973), co-authored with Judith Willer, was a critique of the position advanced in Scientific Sociology. Here the attempt to emulate logical-positivism was abandoned in a scathing critique of empiricism, but little was systematically presented that could take its place. The positive contribution toward a method for advancing theory was formulated in the paper "What is Exact Theory?" (Willer, 1978). Building on the perceived shortcomings of the propositional tradition Willer presented a method that laid claim to the scientific tradition of Galileo, Newton, and Einstein. In contrast to the propositional approach, the method advocated by Willer is significant in that the works of the classical tradition of sociology, particularly Marx and Weber, were once again considered important. In short, the classics were not simply interesting literature but of theoretical significance. This preliminary sketch of the development of theory construction is intended to provide a sufficient contextual awareness for a detailed examination of the major components of each of these views.

\section{PROPOSITIONAL THEORY}

Those authors whom I subsume under the label of propositional theorists all share one determinant characteristic. Each, whether attempting to assert causality or follow the strictures of logical-positivism, equates theories with empirical generalizations. Thus, whether the authors admit this assumption or deliberately ignore it, their entire enterprise subsists on a particular view of the nature of reality, which means their enterprise is valid only to the extent that this view is accurate. Some of the proponents of this school are bolder than others in their advocacy of this world-view. Janet Saltzman Chafetz (1978:35) equates this world-view with science:

\footnotetext{
The scientific process requires the ... assumption that there is order in the universe and that this order is also comprehensible by human beings. If each event, process, and phenomenon were absolutely unique and/or occurred randomly ..., there could be no generalization. Without generalization there is no science. In other words, all sciences attempt to generalize about recurrent phenomena.
}

The essence of this conception of the creation of meaning in science is that theories are human verbalizations that merely express relationships existing in the world. Theory then becomes nothing more than systematic summary statements of empirical regularities that represent processes and events that occur in reality. The goal of theory from this perspective is to link these empirical generalizations into a comprehensive explanation of the world. Each of the proponents of propositional theory shares this world-view, conceives of grand theory as the long-term goal of the sociological project, and holds as a general orientation that the 
proper means to advance theory construction is through the formulation and testing of formal statements.

A number of semantic distinctions give the appearance that the differences among these propositional proponents is greater than actually exists. I intend to ignore these subtle distinctions, since they are more contrived than substantial and would only shift the focus from the essential agreement that characterizes this school. Let it suffice to say that the differences among these proponents center on when to call a proposition an axiom, theorem, hypothesis or postulate, and other such weighty matters. For the sake of simplicity I will adopt the usage of Hubert Blalock and Nan Lin, and outline the general procedures that produce a testable hypothesis.

According to Blalock (1969:2) theories "must contain lawlike propositions that interrelate the concepts or variables two or more at a time." A similar conception is offered by Lin (1976:18), although he emphasizes the relationship between concepts rather than the nomological properties of the propositions themselves. For Blalock, propositions can be divided into two sub-categories: axioms and theorems. Axioms are "untested (or untestable) assumptions" (1969:11), and "imply direct causal links among variables" (1969:18). They provide the basis from which theorems are deduced in accordance with the rules of logic. In comparison with axioms, theorems are state "in terms of covariations and temporal sequences, thereby making them testable". (Blalock, 1969:18). A quote by Paul Davidson Reynolds (1971:69) places this notion in the context of the scientific enterprise as conceived by propositional theorists.

The heart of scientific knowledge is expressed in relational statements. ... Relational statements can be classified into two broad groups, those that describe an association between two concepts and those that describe a causal relation between two concepts.

The emphasis on causality is a primary attribute of this school. Blalock, Chafetz, Stinchcombe (1968), and Wallace (1971) all consider the discovery of causal links an integral objective of science. Although Blalock (1961:6) admits that "causal thinking belongs completely on the theoretical level and...causal laws can never be demonstrated empirically" he nevertheless proceeds to test hypotheses in hopes of making causal inferences. Chafetz, (1978:35) likewise views causality as a felicitous assumption compatible with her prior assumption of an ordered universe:

The assumption of an orderly universe is closely connected to another important assumption made by all sciences.... [S] cientists must assume causality, or the logical connection between perceiveable events, processes, and other phenomena.

The necessity of imputing causality is attributed to the practical need for a foundation of knowledge not based on "pure faith" $(1978: 36)^{2}$

Constructing hypotheses through the axiom-logical deductiontheorem sequence occurs on the theoretical level. The product of this process is an hypothesis stated in the form of a relationship between two or more concepts. In order to test this hypothesis, which constitutes a theory for Blalock, the concepts are linked into a causal model detailing the relationships among the various concepts. This model is then used to help construct regression equations appropriate for the particular causal model.

Before the hypothesis can be tested, each concept must be operationalized. Blalock (1969:153) differentiates the conceptual level from the operational level by the use of labels. He terms the conceptual level of theory the "main theory" and the operational level the "auxiliary theory." Blalock has done nothing unique here and those familiar with empirical methods will recognize an "auxiliary theory" as the product of the assignment of measurable empirical indicators or proxies for the concepts of the theory.

Unlike the strict operationalist approach in which "the concept is defined to be that which is measured" (Bailey, 1978:48), Blalock does not believe that any one, or even a number, of variables adequately capture the essence of a concept, especially not more abstract concepts. He considers this problem inherent in the operationalization of abstract concepts, which makes 
certain simplifying assumptions necessary. Blalock (1969:151) calls this the "measurement problem" and notes that the "auxiliary theory must also contain assumptions concerning the operation of omitted variables that produce both error terms in the equation and measurement errors in each of the variables."

The problems inherent in making these as well as other assumptions necessitates the inclusion of error terms in the regression equations and vigilance in the choice and administration of measurement instruments. Thus, technical competence cannot simply solve the measurement problem, which is predominantly conceptual.

Once the theory has been fully operationalized the verification process can begin. Blalock (1969:11) does not believe that theories can ever be verified "unless all possible competing alternatives can be rejected." Since this possibility is unlikely, (because of measurement error and the potential influence of variables not considered), Blalock (1969:12) concludes that "we shall be in the unfortunate situation of having to proceed by eliminating inadequate theories, rather than ever really establishing any of them." The issue of the falsifiability of hypotheses is characteristic of this school and those who subscribe to this notion believe that this is generally true of all science. They recognize the provisional nature of scientific knowledge and take comfort that, since their knowledge also is provisional, they are equally engaged in the accumulation of scientific knowledge.

This raises a serious problem concerning the goal of ever more comprehensive theories. If the findings of this variety of research are open to falsification, how then is the ultimate goal of grand theory to be accomplished? Zetterberg (1966:127) answers this with the familiar empiricists' palliative: replicability.

The universality of a sociological proposition is an assumption which we have to confirm by extensive replications of our studies.... [W] e have to confirm our propositions on different subject matters... in different categories... before we can claim a hypothesis verified.
Reynolds concurs in this conclusion and makes a useful distinction between an hypothesis, an empirical generalization and a law.

To summarize, if there is as yet no empirical evidence for or against a statement, it is called a hypothesis; if there is moderate support, it is called an empirical generalization; if the support is "overwhelming," it is called a law (Reynolds, 1971:80).

Although Reynolds qualifies the last part of this statement by noting that "overwhelming" evidence may never produce enough consensus to consider a theoretical statement a law, Zetterberg's conception is consistent with Reynolds' characterization of the progression from generalization to scientific law. Zetterberg (1966:14) maintains that "the distinction between findings and laws is one of degree of generality and degree of empirical support."

Blalock (1970:82-83) also embraces this distinction when he states that "the most useful scientific laws ... are ... 'if-then' statements," although the scientific laws of society he offers are hardly comparable to the more familiar "laws of nature" of the physical sciences. For Blalock (1961:17) the laws in the social sciences are statistical in nature, which is to say merely probabilistic, because they are applied "to real-world situations rather than ideal ones. Truly universal laws, holding without exception, can never be expected to apply to real situations because of the influence of disturbing factors."

\section{GROUNDED THEORY}

A second major approach to theory construction has been offered by Glaser and Strauss (1967). They call their approach "grounded" theory, but it could be called "emergent" theory with as much justification. Like propositional theory, the grounded theory technique seeks to develop generalizations from data. Grounded theory, however, breaks with the canons of rigor common to the propositional approach. 
Though Glaser and Strauss $(1967: 6)$ assert that their method of theory construction is phenomenological, their claim to a phenomenological foundation is curious if not misinformed. Glasser and Strauss $(1967: 3)$ do advance a position consistent with phenomenology when they state: "of course, the researcher does not approach reality as a tabla rasa. He must have a perspective that will help him see relevant data and abstract significant categories from his scrutiny of the data." They proceed to contradict this point and neglect the importance of the researcher's perspective in theory construction when they assert that "the categories are discovered by examination of the data" (1967:3).

A more faithful interpretation of the phenomenological approach would stress theory as a creation of human consciousness, since it is human beings and not data that formulate theory. Richard J. Bernstein (1976:128-129) develops this theme at length in The Restructuring of Social and Political Theory. For him, the essence of a phenomenological approach is that the "everyday life-world is pre-scientific not only in that it existed prior to the development of modern science, but also in that it is presupposed in all our scientific endeavors." Taking the point even further, a well-known phenomenologist (Kockelmans, 1978:4) argues that "theoretical activities cannot be described as a 'merely looking at things' (objectivity) which automatically emerges when one refrains from all 'practical' (subjective) concerns." Yet this is the view of theory construction that Glaser and Strauss offer, an outlook consistent with the conception of theory construction held by propositional theorists.

In their tacit support of this view of theory construction Glaser and Strauss reduce phenomenology to the vague reminder that the human mind is an important element in the process of theory construction, and the equally unspecified idea that the researcher is not to impose categories on the phenomena. This oversimplification of phenomenology does violence to the integrity of the grounded theory approach, and accounts for its capitulation to the viewpoint of an empirical epistemology on several crucial issues.

The first concession to the empiricism of the propositional approach is made on the view of the world. Both grounded and propositional theory share the assumption that it is actually the dead weight of the world as it impresses itself on the theorist that permits the empirical regularities of the world to be discerned and formulated into theories. Both Glaser and Strauss and the propositional theorists believe that the world has an objective existence independent of the human mind, in contrast to the phenomenological principle that "objectivity" is a product of human consciousness.

The other two crucial concessions are related and can be summarized as the nature of science and the role of grounded theory in the scientific enterprise. From a phenomenological perspective, Glaser and Strauss would be seen as equating empiricism with science. The differences between an empirical and a phenomenological science cannot be discussed here, but are addressed by Maurice Merleau-Ponty (1967:488ff) in a phienomenological interpretation of the method of Galileo and Newton, and in a more directly sociological context by David Dickens (1979:328ff). The difference between phenomenological science and empirical science is neatly reflected in the irony of an empirical epistemology that proclaims the empirical method as a neutral picturing of reality, and considers the resulting knowledge objective. The irony lies in the fact that empiricists actually approach their research with a formal a priori conception of what is significant. In contrast, the phenomenologist explicitly attempts to avoid preconceptions, while at the same time realizing that preconceptions are inevitable.

The statements of Glaser and Strauss about the relationship of grounded theory to the scientific enterprise reveal that they consider grounded theory as a first approximation toward the goal of science. For instance, Glaser and Strauss (1967:3) assert that "theory should provide clear enough categories and hypotheses so that crucial ones can be verified in present and future research; they must be clear enough to be readily operationalized ... in quantative ways." Glaser and Strauss make many reverential statements about the ways in which grounded theory can serve the ends of verificational studies and thus participate vicariously in the scientific endeavor. An excellent example is provided by Glaser (1969:219) when he said "partial testing of 
the theory .... is left to more rigorous, usually quantitative, approaches which come late in the scientific enterprise." To the phenomenologist, such deference is misplaced, since the results of phenomenological inquiries result in scientific knowledge. This last point is forcefully made by Husserl when he said "it is high time that people got over being dazzled ... by the ideal and regulative ideas and methods of the 'exact' sciences-as though the in-itself of such sciences were actually an absolute norm for objective being and for truth" (quoted in Dickens, 1979:330).

Grounded theory, as formulated by Glaser and Strauss, does not constitute a distinct approach to theory construction simply because it is not consistently phenomenological. If, however, the foreign elements imported from an empirical epistemology were purged, and a consistent phenomenological underpinning provided, grounded theory could be a coherent approach to the generation of theory. If we ignore the philosophical deficiencies and attendant mistakes, the bulk of the descriptive and practical advice given by Glaser and Strauss is of great value.

Probably the most important component of their practical advice is what they call the "constant comparative" method. Glaser and Strauss tout the flexibility of this method and assert that it is best conceived as a process. Rather than the mechanical and formal procedures required of the propositional theorist, a grounded theorist must immerse himself in a social setting and, if no preconceptions distort perception, theory will emerge as a consequence of the experience. Insight is crucial to the success of this venture.

Glaser describes four stages of the constant comparative method, three of which are relevant here. In the first stage the researcher begins by coding each incident and event by creating as many categories as possible. Once this process has begun, the researcher must compare each new incident with other incidents coded in the same category. Thus, this stage entails constant comparison of each incident with every other. Shortly after this process has begun the

constant comparison of incidents ... starts to generate theoretical properties of the category. One starts thinking in terms of the full range of types or continua of the category, its dimensions, the conditions under which it is pronounced or minimized, its major consequences, the relation of the category to other categories, and other properties of the category (Glaser, 1969: 221).

In the next stage of the method an actual theory begins to emerge as the relationships of categories and properties become apparent. Glaser (1969:221-22) characterizes the comparisons in this stage as a "change from comparison of incident with incident to incident with properties of the category which resulted from initial comparison of incidents" during the first stage of the process. It is in this second stage that theory begins to emerge:

Thus the theory develops as different categories and their properties tend to become integrated through constant comparisons which force the analyst to make some related theoretical sense of each comparison (Glaser, 1969:222).

In the third stage of the process, the theory becomes delimited at the theoretical and the categorical levels.

First, the theory solidifies in the sense that major modifications become fewer and fewer as one compares the next incidents of a category to properties of it (Glaser, 1969:222).

Second, the categories are delimited in two respects. In one, the number of categories become limited, either through consolidation or elimination of categories not theoretically relevant. A second type of categorical definition is even more important, and is an indication that the usefulness of fieldwork may be ending. Glaser terms this the theoretical "saturation" of the categories. Glaser (1969:223) explains it in this manner:

After one has coded incidents for the same category a number of times, it becomes a quick operation to see whether or not the next applicable incident points to a new aspect of the category. 
In particular, negative cases are extremely important when making a decision about whether the theory is complete or needs work. If negative cases can be subsumed by the theory, and if the categories have become "saturated" to the point that little advantage will result from more study, then it is time to leave the field and formally compose the theory.

Glaser and Strauss (1967) identify two elements of theory, the first of which is relevant to my purposes here. The first is the set of conceptual categories and their conceptual properties. Following Blumer (1964), Glaser and Strauss state that concepts should have two "essential features." Concepts should be analytic, that is to say indicative of characteristics of concrete entities, and sensitizing, which is to say they should provide a meaningful frame of reference for those engaged in the social setting.

Since grounded theory prescribes a method in which the generation of theory is the goal, a number of issues that are important to propositional theorists also have significance for those constructing grounded theories. In contrast to the emphasis propositional theorists place on the falsifiability of theories, Glaser and Strauss $(1967: 232)$ realize that theories are neither true nor false: "It is not correct to say that because a theory 'does not fit' a structure, then it is invalid." The reason for this was given in an earlier passage: "[E] vidence and testing never destroy a theory (of any generality), they only modify it. A theory's only replacement is a better theory" (Glaser and Strauss, 1967: 28).

Neither is the kind of evidence or the number of cases crucial for generating theory. Glaser (1969:218-19) responds to the issue of the replicability of the results, although indirectly, when he admits that "the constant comparative method is not designed... to guarantee that two analysts working independently with the same data will achieve the same results." The reason for this is that theory is a process and hence historical and developmental. For the grounded theorist the goal of a frozen universal empirical generalization (a "law of society") is impossible. Propositional theorists lament that not much progress has been made toward their goal and that their immature science calls for more disciplined and rigorous methods. For the grounded theorists the entire project of theory construction promoted by propositional theorists is wrong because history and change are not considered integral to social phenomena.

As a final point of comparison with propositional theory, Glaser does not consider the constant comparative method appropriate for testing hypotheses. Since the goal is to generate theory that is unique and a product of the research process "the approach presented here cannot be used for provisional testing as well as discovering theory" (Glaser, 1969:219).

\section{EXACT THEORY}

The starting point of exact theory is a critique of the empirical world-view that has dominated the social sciences for the last three decades. Exact theory is not based on empirical generalizations nor any assumption about the regularity of the universe. In contrast to propositional theorists who believe that "generalizations are ordered by phenomena ... [e] xact theory orders phenomena" (Willer, 1978:3). This means that theories are not summary statements about the regularities that exist in the world but are products of rationality. Willer claims that this is consistent with the way in which theories are used in the natural sciences.

Stephen Toulmin (1953:43) provides support for this view when he observes that

discoveries in the physical sciences consist in the introduction of fresh ways of looking at phenomena and in the application of new modes of representation, rather than in the discovery of new generalizations.

In other words, it is not the regularities of the world that determine the terms of a theory. Instead, theory orders phenomena by providing a new interpretation of the phenomena. It is theory that determines which empirical phenomena will be considered and which will be disregarded. Willer (1978:12) clarifies this further when he states that "once a theory is formed, it serves as a guide to observation. It tells us what to observe and what to ignore." 
Unlike the method of theory construction proffered by propositional proponents, but consistent with what is known about some of the most revolutionary innovations in scientific theory, exact theory reserves a central place for the role of insight or a purely rational component in theory construction. ${ }^{3}$ It is within this context that Einstein's assertion that theories "are free inventions of the human intellect" (quoted in Willer and Willer, 1973:11) can be understood.

With these considerations in mind, Willer consciously seeks to cast exact theory in the mold of the theoretical enterprise of the physical sciences. To accomplish this he returns to the writings of the early creators of the natural sciences and concluds that three features are essential to the construction of theories. He identifies a modeling procedure, theoretic principles, and a theoretic calculus as the fundamental components of exact theory, each of which is unique to this method of theory construction.

Consciously emulating the procedures used by Galileo, Willer recommends devising a model as the first step in the attempt to create an exact theory for a phenomenon. For Willer, a model has a decisive purpose:

[M] odels generated from the theories are structured representations of the relationships dictated by the theories. Conversely, the creation of a useful theory requires the abstraction of a pure structural model from the diverse material of observation (Willer and Willer, 1973:24).

In short the model is the crucial link between empirical phenomena and theory, and represents both. The model accomplishes this task through a geometrical representation of both the theoretical and empirical levels, and contains only what is theoretically relevant while simultaneously charting the relations of the real world in abstract form. According to Willer, the modeling procedure provides exact theory with the ability to extend a theory's application beyond the limitation common to empirical generalizations. In contrast to theory based on empirical generalizations, in which the theory can be extended only to empirical phenomena
Theory Construction

that are similar to one another, exact theories can be applied to a broad range of phenomena at an abstract level. The range a phenomena to which the theory can be applied constitutes the "scope" of the theory.

The second element of exact theory is the set of theoretic principles, none of which are empirical generalizations. Theoretic principles are not expression of regularities of the world. These principles are specifications of crucial idealizations of the phenomena to be theorized about. Interpreted literally, these principles would either be wrong or make no sense. An example offered by Willer is the principle from theoretical optics specifying that "light travels in straight lines." Anyone with even a rudimentary knowledge of optics can think of a number of instances where this is simply not true. Therefore, as an empirical generalization it is worthless, but as a simplifying assumption it is valuable in "estimating the proper scope of application of the theoretic system" (Willer, 1978:8).

The third element of exact theory, the theoretic calculus, expresses the terms and relations of the theory. As conceived by Willer (1978:10), the "calculus of any exact theory consists of a set of formal statements, normally presented in mathematical form." Unlike the use of mathematics in the propositional approach, theoretic calculi do not contain probabilities but are stated in terms of equivalence. This is possible because "the principles and calculus of the theory are not applied directly to data but to the model itself". (Willer, 1978:8). The obvious advantage of this is that an exact theoretic calculus will permit an exact calculation and therefore an exact prediction of possible results. This exact calculation enables a comparison of the model with the empirical phenomena in question in order to assess the explanatory power of the model. Once the model has been compared with the empirical phenomena a determination commade about the "scope" and "isomorphism" of the theory. Both the scope and isomorphism are important criteria and govern the validity of the theory in each of its applications. Willer explains
these criteria: 
To the extent that the theory ... successfully orders the data of the empirical instarice in question, that theory is said to be isomorphic. The extent of isomorphism in any given application is the measure of the precision of the theory. The range of instances to which the theory can be precisely applied is the measure of the scope of the theory. The evaluation of any exact theory is based jointly upon its precision and its scope (Willer, 1978:5).

It is important to note that theories of limited scope and isomorphism are in no way falsified. Since exact theories are not empirical generalizations they cannot be refuted by empirical events. There is essential agreement with Glaser and Strauss on this point. The issue is not one of truth or falsity but of applicability. Does the theory adequately explain and predict the empirical phenomena? If so then there is no need to repeat the study since replicability, the piling on of confirming instances, is pointless unless one suspects a significant change in conditions. An exact theorist would have no interest in repeating the test of the theory under the same circumstances because the importance of an exact theory is determined by the range (scope) of phenomena it can explain and predict. An exact theorist is always looking for new tests to perform.

A second area of divergence with propositional theory is over the issue of causality. According to Willer and Willer (1973: $20 \mathrm{ff}$ ), the discovery of causal connections is not the goal of science. Analysis of laws from the natural sciences reveals that scientific laws are determinative, not causal. This viewpoint is also held by Toulmin, and he called attention to the relative absence of the concept of causality in scientific writing as evidence. Toulmin (1953:120) affirmed that the interest in causality was an essentially pragmatic one that reflected an interest "in producing, preventing or counteracting.... Correspondingly, to discover the cause ... is to find out what it is that needs to be altered, if we are to produce, prevent or counteract."

A corollary issue that serves to distinguish propositional and exact theories is the issue of probability. The name of exact theory is derived from this important distinction. Willer (1978:11) emphasized this point: "No theoretic calculi contain probabilities." This means that the sophisticated statistical tests used by propositional theorists to compare the results with the likelihood that the outcome is attributable to chance are inappropriate. To an exact theorist, comparing everything with the likelihood that it is merely accidental exhibits the poverty of the propositional approach. Because exact theory is not based on probability, predictions can be made for individual cases. This is generally untrue of statistical predictions, which refer to hypothetical or actual populations. The best statisticians can do is estimate the likelihood of an occurrence. This, however, does not adequately map a real world in which things do not "probably" happen. Events either occur or they do not.

As I have attempted to show, exact theory and propositional theory are diametrically opposed. The only common feature they share is the goal of all science, prediction and explanation, but this is not enough to reconcile the differences between them. However, this discordance need not characterize relations between grounded theory and exact theory, since they share some fundamental elements.

Although Willer does not develop this aspect of exact theory, his method shares some features with the phenomenological approach to the world. For Willer, theory is created through an abstractive process that bridges the empirical and rational. Although he emphasized the construction of theory as a "free invention" of the human mind, this is a purposeful overstatement designed to refute the technical approach that currently dominates sociology. It is obvious that Willer does not contend that no knowledge of the world is necessary to produce theories. Thus, with the qualification that each of us shares a pre-scientific view of the world as conscious human beings, the position of exact theory is similar to the constructivist emphasis of the phenomenological approach, and the role of intuition is provided a philosophical grounding.

Consideration of human motivation, or the "actor's preference states" as Willer (1978:31ff) terms them, is a second element of exact theory resonant with a phenomenological approach. Unlike the behaviorist position in social science, the 
operation of mind and human values are important, and must be considered whether or not values always determine behavior. In other words, what human beings think and believe are important to the theoretical project.

A final area of convergence is the indispensable role of "abstractive" thinking. Willer and Willer (1975:12) explain this by making reference to "Plato's postulation of a world of forms in which the diversified objects of experience are reflected in a pure idea, or form, which those objects resemble but never achieve." Willer and Willer (1973:13) provide a modern analogue of this for sociology in Max Weber's ideal types.

A similar recognition of this profound contribution to sociology comes from phenomenology. Joseph Kockelmans provides support for the construction of ideal types in language congenial to the exact theorist.

[I] deal types are means to the end of understanding phenomena.... Weber contrasts his own position with the view according to which it is the end and goal of every science to order its data into a system of concepts, the content of which is to be acquired and slowly perfected through the observation of empirical regularities, the construction of hypotheses, and their verification, until finally a 'complete' and hence deductive science emerges. According to this view the concepts are the ends and not the means of understanding the phenomena. For those who fully perceive the implications of the fundamental ideas of modern epistemology which ultimately derives from Kant, namely, that scientific concepts are primarily analytical instruments for the intellectual mastery of empirical data and can only be that, the fact that precise concepts are necessarily ideal types will not cause them to desist from constructing them (Kockelmans, 1978:12-13).

This is the quintessence of exact theory and reflects a basis for a claim to a phenomenological foundation. As Kockelmans states: standing ... between the purely formal concepts of the a priori framework of meaning and the concrete historical phenomena to be explained empirically ..., ideal types are capable of mediating between social theory and our explanation of the social 'facts' which occur in a given society (Kockelmans, 1978:14).

I have emphasized the similarities between a philosophically consistent grounded theory and exact theory, and believe these points of convergence are important. The epistemological foundations of their view of theory construction exhibits a more selfconscious awareness of the limitations of knowledge than is true of the adherents of the propositional approach. Whether this results in better social theory remains to be seen, since practitioners have the tendency to reduce an epistemology to a technique, as is especially true of propositional theorists. As I have mentioned, Willer does not deal with the role of the researcher in any detail; further, without an explicit account of the relationship of knowledge and experience, exact theory has the danger of lapsing into an untenable position maintaining that knowledge without experience is possible. I have suggested that a phenomenological explanation could resolve this problem, but exact theory should address this issue and make the relationship explicit.

In comparison, propositional theory combines the worst aspects of an unjustified epistemological self-confidence with a narrow focus on technique. Of the three types of theory construction that I have presented, certainly the propositional approach is the most accepted and has the most adherents. The identification of this approach with proper sociological method could be offered as evidence that sociology is a normative discipline, and indeed the propositional method is transmitted to sociological neophytes with more normative content than critical examination of the epistemological foundation upon which the method is based. One need only compare the enormous efforts that have been devoted to the refinement of techniques with the meager theoretical results in order to question teaching this method as if its transformation to full maturity had already occurred.

The fatal weakness of the propositional approach, its implicit belief that observation is a neutral picturing of reality, 
touches on the strength of the phenomenological method, which is the realization that observations are always theory laden. In other words, observations are possible precisely because, not in spite of, the observer's structuring of reality through experience. This dilemma is presaged by Kant $(1928: 41-42)$ in the introduction of the Critique of Pure Reason when he addressed the issue of the relationship of experience and knowledge:

There can be no doubt that all our knowledge begins with experience.... [W] e have no knowledge antecedent to experience, and with experience all our knowledge begins. But though all our knowledge begins with experience, it does not follow that it all arises out of experience.

Empiricists, including propositional theorists, resolve this dilemma by dogmatically adhering to the first part while ignoring the admonition that knowledge is not simply a product of experience. The strength of a phenomenological approach is that it attempts to explain the relationship of knowledge and experience in terms of the active role of the observer in interpreting experience through a theoretic structure.

\section{NOTES}

1. This general conception of theory is recognizable under a number of different rubrics. Two of the most prominent are propositional theory and axiomatic theory. Each of these approaches shares essential features that permit them to be treated as a unified approach. The most important of these is the empirical epistemology that forms the basis for theorizing. Other elements that contribute to the empirical basis are logical-deductive arguments, emphasis on the verification of hypothesis, and the testing of causal models.

2. Chafetz is well aware that the assumptions of an orderly universe and causality can not be empirically verified, and must therefore be based on faith. The irony of invoking these "assumptions" and the faith in the world-view they entail is constantly revealed and at the same time concealed by all empiricists who do not honestly confront the limits of their epistemology. Chafetz obscures this issue by a justification of the scientific method based on "common sense." According to Chafetz, these assumptions and the scientific method are valid because they are "part and parcel of the everyday lives of all people" (1976:36). It would be convenient if things were this simple. Unfortunately, truth is not a plebiscite, and whether everyone actually behaves as if the world is ordered and events are causally linked can provide no firmer basis for an epistemology than "pure faith." The validity of science must be based on something more substantial than consensus.

3. It is interesting to note that both Blalock, and Glaser and Strauss also mention intuition as a component in theory construction but only as a grudging concession since intuition can have no logical place in an empirical epistemology. It should be recognized that intuition is quite different for Willer than it is for any empiricist, since Willer's conception is of a creative intuition.

\section{REFERENCES}

Bailey, Kenneth D.

1978 Methods of Social Research. New York: Macmillan.

Bernstein, Richard J.

1976 The Restructuring of Social and Political Theory. Philadelphia: University of Pennsylvania Press.

Blalock, Hubert M.

1961 Causal Inferences in Nonexperimental Research. New York: Norton.

1969 Theory Construction: From Verbal to Mathematical Formulations. Englewood Cliffs, New Jersey: Prentice-Hall.

1970 An Introduction to Social Research. Englewood Cliffs, New Jersey: Prentice-Hall.

Blumer, Herbert

1954 "What is wrong with social theory?" American Sociological Review 19:3-10

Bruyn, S.T.

1967 "The new empiricists: the participant observer and phenomenologist." Sociology and Social Research 51:317-22.

Chafetz, Janet Saltzman

1978 A Primer on the Construction and Testing of Theories in Sociology. Itasca, Illinois: F.E. Peacock Publishers.

Dickens, David R.

1979 "Phenomenology." Pp. 325-347 in Scott G. McNall (ed.), Theoretical Perspectives in Sociology. New York: St. Martin's.

Glaser, Barney G.

1969 "The constant comparative method of qualitative analysis." Pp. 216-228 in George J. McCall and J.L. Simmons (eds.), Issues in Participant Observation: A Text and a Reader. Reading, Massachusetts: Addison-Wesley. 
Mid-American Review of Sociology

Glaser, Barney G. and Anselm L. Strauss

1967 The Discovery of Grounded Theory: Strategies for Qualitative Research. Chicago: Aldine.

Kant, Immanue

1929 Critique of Pure Reason. Norman Kemp Smith (trans.). New York: St. Martin's.

Kockelmans, Joseph J.

1978 "Reflections on social theory." Human Studies 1:1-15.

Lin, Nan

1976 Foundations of Social Research. New York: McGraw-Hill.

Merleau-Ponty, Maurice

1967 "Difficulties involved in a subordination of psychology." Pp.485501 in Joseph J. Kockelmans (ed.), Phenomenology. Garden City, New York: Doubleday.

Merton, Robert K.

1949 Social Theory and Social Structure. New York: Free Press.

Reynolds, Paul Davidson

1971 A Primer in Theory Construction. Indianapolis, Indiana: BobbsMerrill.

Stinchcombe, Arthur L.

1968 Constructing Social Theories. New York: Harcourt, Brace, and World.

Toulmin, Stephen

1953 The Philosophy of Science: An Introduction. New York: Harper and Row.

Wallace, Walter L.

1971 The Logic of Science in Sociology. Chicago: Aldine.

Willer, David

1967 Scientific Sociology: Theory and Method. Englewood Cliffs, New Jersey: Prentice-Hall.

1978 "What is exact theory?" In Robert Smith and Bo Anderson (eds.), Theory Development. New York: Halstedt Press.

Willer, David and Judith Willer

1973 Systematic Empiricism: Critique of a Pseudoscience. Englewood Cliffs, New Jersey: Prentice-Hall.

Zetterberg, Hans L.

1966 On Theory and Verification in Sociology. 3rd. edition. Totowa, New Jersey: Bedminster Press.
PROTESTER DESOCIALIZATION AND THE FRAGILITY OF AMERICAN POLITICAL INSTITUTIONS

\author{
David Kowalewski \\ University of Kansas
}

Mid-American Review of Sociology, 1980, Vol. V, No. 1:37-53

Numerous studies of American New Left activists have greatly increased our understanding of political protest phenomena. Particularly our comprehension of the sociological and psychological characteristics of protesters has been significantly enhanced (Keniston, 1968; Hampden-Turner, 1971). However, as some researchers have noted (Szliowicz, 1972:6-9), protesters' characteristics have been emphasized to the virtual exclusion of political variables.

While protest theorists (Useem, 1972) have frequently observed that a good deal of ideological change takes place during activists' protest careers, detailed studies of changes in the political attitudes of New Leftists over time have been notably absent. Whereas the processes by which political systems socialize the young into acceptance of prevailing political institutions have been extensively studied (Dawson and Prewitt, 1969; Langton, 1969), little attention has been devoted to the processes of desocialization.

For several reasons we should expect that regime socialization of the young is not always permanent. In their study of 5600 citizens in six developing countries, Inkeles and Smith (1974) found that individuals are not as resistant to political change after childhood as expected. Modern political attitudes are heavily influenced by experiences in later adolescence and early adulthood. Moreover, the Third World citizen's later acceptance of modern political attitudes tends to be enduring and irreversible.

Involvement in New Left protest activities by young citizens can be expected to result in significant ideological movement away from acceptance of the regime's political institutions. First, as Erikson (1970:164) noted, ideological experimentation is a 